Research Article

\title{
Community Public Safety Evaluation System Based on Location Information Service Architecture
}

\author{
Zili Zhao \\ School of Government, Peking University, Beijing 100871, China \\ Correspondence should be addressed to Zili Zhao; 1906389399@pku.edu.cn
}

Received 30 November 2020; Revised 23 December 2020; Accepted 7 January 2021; Published 28 January 2021

Academic Editor: Chi-Hua Chen

Copyright ( 92021 Zili Zhao. This is an open access article distributed under the Creative Commons Attribution License, which permits unrestricted use, distribution, and reproduction in any medium, provided the original work is properly cited.

\begin{abstract}
The establishment of communities is for the better operation and management of cities, and community safety has gradually become a topic of increasing concern. It is not only an important part of the community public safety system, but also the foundation of social and economic development. With the improvement of the overall economic level of society, wireless network coverage has been greatly improved, smart devices have also been rapidly developed and popularized, and location-based information service systems have gradually entered the field of community public safety. At present, my country still lacks experience in community safety management. At the same time, there is no complete set of standards and evaluation system for the public safety evaluation system of urban communities. However, community public safety involves people's livelihood issues and the stability and development of the city. Therefore, it is urgent to build a community public safety evaluation system based on the location information service architecture. Based on the safety community research and location service system, this paper uses the combination of theory and practice, quantitative and qualitative methods, and tentatively explored and constructed a community public safety evaluation system based on the location information service architecture. This article integrates location information service technology into the community public safety evaluation system, selects three indicator factors, investigates a more comprehensive evaluation subject, and combines the evaluation subject's qualitative evaluation of community public safety with quantitative evaluation through fuzzy comprehensive evaluation. This paper conducts an empirical analysis of a certain community and finds that its public safety evaluation score is 62.6232 points, which is in the "general" ranks, and it needs to be combined with the location information service system to improve the community safety issues. This study has guiding significance for ensuring community public safety and has theoretical and practical significance for community construction and development.
\end{abstract}

\section{Introduction}

Communities are the carriers of people's lives. With the expansion of cities, the frequency and scale of emergencies and disasters have increased rapidly, and community public safety has attracted much attention. Community public safety includes all aspects of production, life, environment, education, and so on that takes place in the jurisdiction. It is closely connected with community construction. The purpose of establishing a community public safety evaluation system is to analyze the current status of community safety management and construction and its impact on the community, so as to take effective measures to avoid losses and adverse effects.
With the development and application of wireless network technology, location-based network information services have also developed soundly. This kind of location information service is referred to as LBS for short. It means using the current positioning technology to get the location information needed and then achieve a certain purpose through the local area network to achieve a certain service. The initial LBS system is mainly used in emergency situations, can quickly locate the location information of the victim, and achieve rapid rescue operations. Now, the shaping of LBS technology can be applied to transportation, medical, military, and other fields. LBS service is contextaware and adaptable, which is what distinguishes it from traditional network services. Context awareness means that, 
it can obtain any information about an entity. Taking mapbased mobile services as an example, it includes user information, specific location, use time, and use purpose. Its adaptability can be divided into 4 levels: information level, technical level, user interface level, and display level.

$\mathrm{Yu}$ proposed a different method for colocation mining using the network configuration of the considered geographic space. The spatial colocation mode represents a subset of the spatial features, and the objects of these spatial features are usually located in a tight geographical area. For geographic context awareness of location-based services (LBS), this model is one of the most important concepts. In the literature, most of the existing colocation mining methods are used for events that occur in a homogeneous and isotropic space, and the distance is expressed as Euclidean, and the physical movement in LBS is usually constrained by the road network. As a result, the interest value of the colocation mode involving network restricted events cannot be accurately calculated [1]. Tulumello contributed to the recent discussion on the convergence/divergence of local policies on urban safety and public safety in globalization, exploring relatively localized crime prevention methods, and explaining the similarities and differences through multilevel connections. He analyzed the situational prevention, social policy, and neighboring/community policing in two "nonglobal" metropolises: in Lisbon, safety is the goal of a wide range of policies in many areas; in Memphis, social issues have become the only issues of safety and security game. Based on the political tradition, the neoliberalization of policies, the multilevel relationship between political systems, and different methods are explained. $\mathrm{He}$ discussed the implications of the relationship between policy and policing: the police tried to conduct social propaganda under the combination/decoupling of security and urban policies and the "task crawling" of policing (which is expected to lead to prevention work). However, it has not completely solved the practical problems of community public safety [2]. An example researched by Lapsley is that compared with Victoria, the impact and consequences of bushfires in California and the characteristics and risks of bushfires in California have many similarities, and parts of California have suffered huge lives and property damage. Property for several years in a row. In particular, the Woolsey Fire in California in 2018 destroyed most of Los Angeles and Ventura County, especially Malibu and Calabasas. Community members admitted that they lived in some of the most fire-prone areas, understand the fire. It will happen again and the result will be the same or worse. However, he only studied the safety problems caused by the environment to the public, and the research scope is too narrow for the construction of the public safety system [3].

Aiming at the status quo of the existing community public safety in our country, combined with the location information service system, this article mainly uses the fuzzy comprehensive evaluation method and the method of social investigation to study the community public safety evaluation system. Specific innovations can be summarized as follows: (1) include community residents in the scope of the evaluation subject, fully consider the subjective feelings of community residents, and reflect the integrity of the evaluation subject; (2) this article will affect the objective factors and public safety of the community. The combination of subjective factors can more comprehensively reflect the status quo of community public safety.

\section{Method of Community Public Safety Evaluation System Based on Location Information Service Architecture}

The essence of community research is to conduct social survey research, so it can be applied to any social research method. The community research method must conduct investigation and evidence collection research from multiple angles, multiple dimensions, and multiple levels, including basic methodology, empirical analysis, and specific skills [4]. The basic methods are social survey method, questionnaire method, observation method, and mathematical-statistical analysis method. [5]. In the specific construction and actual evaluation of the index system, this paper uses the specific methods of fuzzy evaluation and social survey.

2.1. Social Survey Method. Social survey method is a kind of social cognition activity, which refers to obtain relevant information needed in reality through the use of survey methods such as census, sample survey, and case survey and to make research analysis reports on the data [6]. It is one of the methods commonly used in empirical research, and its investigation objects are objective facts and subjective facts. The purpose of using the social survey method in this article is to reveal the status quo of community public security through the study of community public security, find out the main reasons that affect its development, and seek ways to reform. Under the guidance of this purpose, this article chooses the method of sampling survey, which is to randomly select the part of the data from the sample population to reconstitute the sample set, then discuss the analysis results, and finally push the results from special to general and from part to overall [7].

\subsection{Fuzzy Comprehensive Evaluation Method. Fuzzy com-} prehensive evaluation method is a mathematical model that uses specific methods of fuzzy measurement, fuzzy statistics, and fuzzy evaluation in the process of calculation. It can be used to solve the evaluation problem of a fuzzy phenomenon [8]. The theoretical methods of sets and fuzzy mathematics can be used to digitize the fuzzy quantity in practice for quantitative evaluation. It has extremely wide applications in multifactor evaluation problems. In actual work, certainty and uncertainty often appear. Uncertainty phenomenon has random uncertainty and fuzzy uncertainty and the latter is difficult to solve with precise mathematics; so effective exploration must be carried out with the help of method theory in fuzzy mathematics to solve the problem of fuzzy uncertainty [9]. Fuzzy and uncertain phenomena can be seen everywhere in industrial production, corporate management and other production, and social practices. It effectively applies the theory of fuzzy mathematics to practical 
problems and has the characteristics of simple method and wide application. It mainly includes a single-factor set evaluation and multilayer factor set evaluation methods [10].

2.2.1. Single-Factor Set Evaluation Method. Set factor set $U=\left\{U_{1}, U_{2}, \ldots, U_{n}\right\}$, judging set (decision set) $V=\left\{v_{1}, v_{2}, \ldots, v_{n}\right\}$, and weights $A=\left\{a_{1}, a_{2}, \ldots, a_{n}\right\}$.

Single-factor evaluation is as follows:

$$
U_{i} \mid \longrightarrow f\left(U_{i}\right)=\left(r_{i 1}, r_{i 2}, \ldots, r_{i m}\right), \quad i=1,2, \ldots, n .
$$

The single-factor evaluation matrix is

$$
R=\left(\begin{array}{cccc}
r_{11} & r_{12} & \cdots & r_{1 m} \\
r_{21} & r_{22} & \cdots & r_{2 m} \\
\cdots & \cdots & \cdots & \cdots \\
r_{n 1} & r_{n 2} & \cdots & r_{n m}
\end{array}\right)
$$

Take the max-min composite operation to get a single-factor evaluation

$$
B=A \cdot R=\left(b_{1}, b_{2}, b_{3}, \ldots, b_{m}\right),
$$

among them,

$$
b_{j}=\bigvee_{i=1}^{n}\left(a_{i} \wedge r_{i j}\right), \quad j=1,2, \ldots, m .
$$

Normalize B in Equation (2). If the judgment set is expressed in quantification, that is, $V=\left(k_{1}, k_{2}, \ldots, k_{m}\right)^{T}$. Then, the total score for a single-factor is $\left(b_{1}, b_{2}, \ldots\right.$, $\left.b_{m}\right)\left(k_{1}, k_{2}, \ldots, k_{m}\right)^{T}$.

\subsubsection{Multilayer Factor Set Comprehensive Evaluation} Method. First, put the total factors together $U=\left\{U_{1}, U_{2}, \ldots, U_{n}\right\}$, split into a multilevel factor set, and then, starting from the highest level, use the single-factor set evaluation method in the above method for layered evaluation, and finally, get a comprehensive evaluation B. Normalize B, and if the evaluation set is expressed in quantification, then the comprehensive evaluation total score of the multilayer factor set can be obtained.

Generally speaking, the application of the fuzzy evaluation method is mainly to establish the evaluation matrix and establish the weight and the comprehensive evaluation result. The index system established in this paper is divided into three levels. The next level is the refinement of the previous level. Therefore, this paper adopts a multilayer factor set comprehensive evaluation method [11].

\subsection{Community Public Safety Evaluation Method Based on} Location Information Service Technology. The basis of location-based information services is the high-speed and efficient collection and reading of location information. The positioning technology mainly includes the following three types: satellite positioning technology, network-based positioning technology, and perception positioning technology [12].
Satellite positioning technology refers to the technology that reads data through artificial satellites in space after selecting objects and finally transmits specific positioning information [13]. Its typical representative technology is GPS. It can locate the target object through the three coordinates of longitude, latitude, and height forming a threedimensional information network. Other improved technologies include differential GPS technology and assisted GPS technology [14]. In general, GPS will be hindered by physical objects such as buildings, resulting in inaccurate positioning accuracy.

Network-based positioning technology is based on a network base station to determine the location information of a target object. In an area covered by a network, when the target object is sensed using a mobile terminal device, the network base station will automatically calculate the object. The specific location information is typically a mobile base station (such as GSM and CDMA). Therefore, this positioning technology is very dependent on the number and coverage of network base stations. In addition, you can also rely on a wireless local area network for positioning, such as Wi-Fi. The accuracy of this method largely depends on the number and location of reference points selected $[15,16]$.

Perceptual positioning technology refers to the installation of sensors in a certain space in advance, as long as a moving object enters its area, its location information can be located, a typical representative is radio frequency identification technology (RFID). The area where RFID is used is very small, so it is only suitable for short-distance identification and indoor positioning, and more consideration needs to be given to indoor space planning and design [17].

The representative technologies of the three positioning technologies are shown in Figure 1.

\section{Experiment on Community Public Safety Evaluation System Based on Location Information Service Architecture}

\subsection{LBS Middleware Model}

3.1.1. Content-Based Model. In this model, a group of events can be regarded as a group of attributes (or called a pair), and the behavior of a subscription request is a predicate related to the event. When an event occurs, it will automatically check all the predicates that made the request. If it is determined that the predicate is true, the event can be sent to the users who need it. Because this model is too simple, there is no program to save historical records or historical subscription requests [18].

3.1.2. Model Based on Topic Space. The focus of this model is the subject space, which is equivalent to a multidimensional space body, which can be divided into various dimensions and defined. A dimension is a primitive ancestor $d=\{$ name, type $\}$ (name represents a unique identifier and type represents the selected data type). Compared with the previous model, this model can retain published information well and supports real-time status publishing of subscribers 


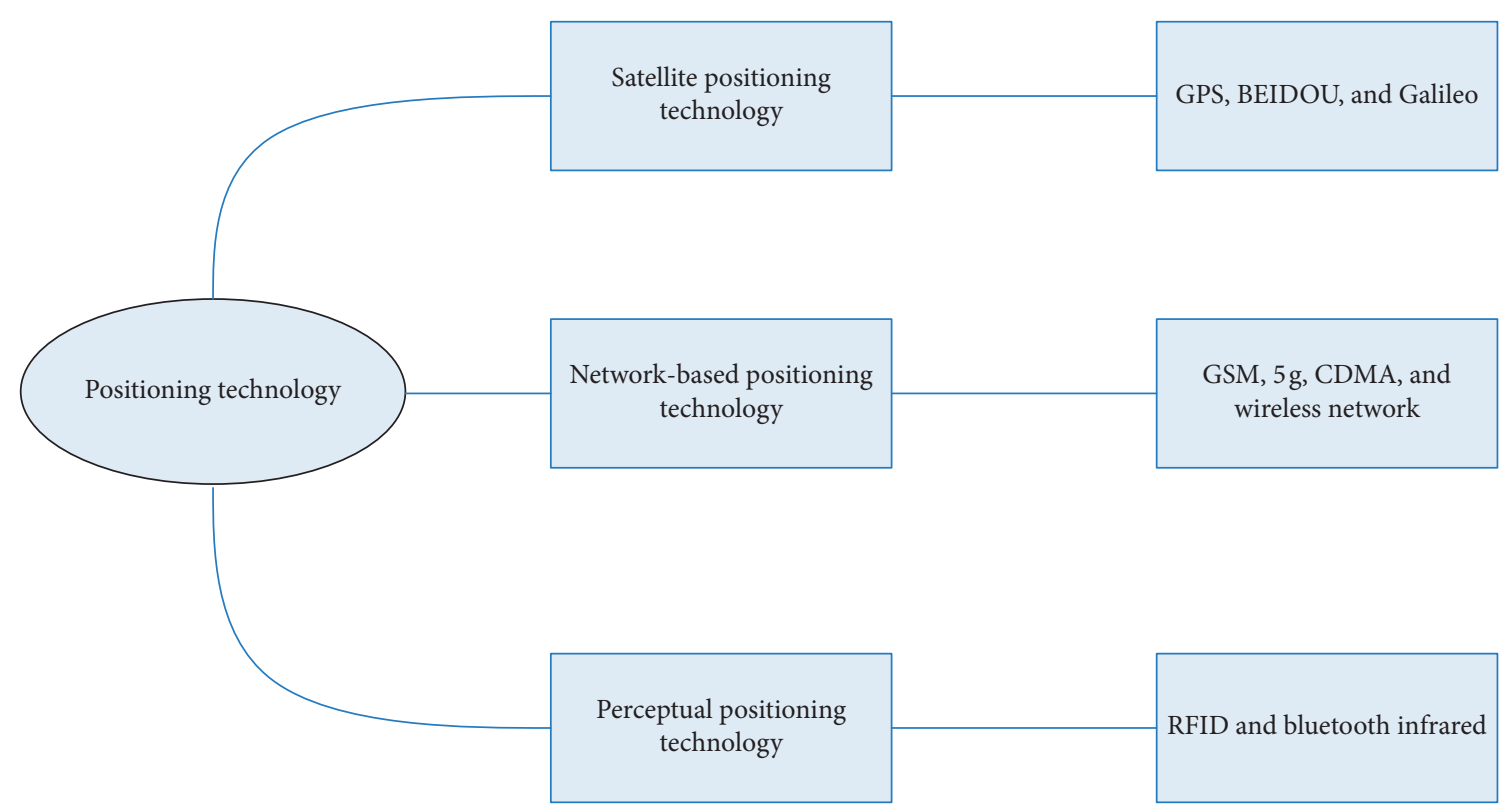

FIgURE 1: Representative techniques of the three technical methods.

[11]. This model can improve the matching degree of information and reduce the frequency of sending information multiple times.

3.1.3. Meta-Ancestral Space Model. This model is essentially a collection of many ancestors, which contains a vector of multiple values. Its application range was first in the field of parallel programming, used to coordinate events and issue execution tasks [19]. The communication in each event is carried out in a primitive space, which is composed of multiple tasks, and the communication is completed by changing or adjusting the values. Normally, each task is independent and decentralized. Therefore, if you want to achieve real-time communication between tasks, you must wait for a response between task A and task B. Using the meta-ancestral space model in the LBS system, the publisher and receiver of the information can well complete the realtime communication in the meta-ancestral space.

3.2. Construction of Community Safety Evaluation System. The construction of a set of evaluation systems involves the subject of evaluation, evaluation content, evaluation method, and evaluation process. The construction of the community public safety evaluation system, combined with the characteristics of community organizations and the needs of urban community public safety, discussed the above aspects.

3.2.1. Composition of the Main Body of Community Safety Evaluation. Generally speaking, the evaluation subject related to the community generally consists of four parts, one is experts and scholars, social intermediary organizations; the second is quasi-community management organizations such as community residents committees and property management companies; the third is government departments represented by streets; the fourth is community residents' organizations [20]. It can be seen from the composition of traditional subjects that individual residents have not received due attention, which also shows that the current community evaluation indicators are still focused on objective aggregate indicators, while the subjective factors of community residents have not been given due attention. This article adds community residents who can be the subject of community safety evaluation as the subject of evaluation, mainly referring to the permanent population of the community.

The social significance of taking residents as the main body of community public safety evaluation lies in (1) improving the residents' participation evaluation mechanism and reflecting the harmonious atmosphere of the community. Residents use their identities, rights, and qualifications to participate in community public safety management affairs, which can enable residents to have a deeper sense of ownership, and at the same time can resolve social conflicts of interest and build a harmonious society [21]. (2) Exploit the resources of community residents and improve the community prevention network. The awareness of the main body of community residents is awakened, which is equivalent to maximizing the resources of community residents. Community residents can be regarded as the axis of community security, building a community prevention network, and returning the power of community crime control to the community. (3) Integrate into the community public safety management system and develop self-defense. The safety management of individual community residents is mainly to develop self-defense, that is, to strengthen doors and windows, properly keep cash and valuables, and implement various safety precaution systems. The purpose is to improve the portal's ability to defend against criminal activities [22, 23]. 
3.2.2. Principles and Characteristics of Community Safety Evaluation Index System. The purpose of establishing the evaluation index system is to have a comprehensive description and evaluation of the state of public safety in urban communities. Therefore, when constructing a community public safety evaluation system, certain basic principles should be followed, and at the same time, the characteristics of public safety evaluation should be reflected [24].

On the basis of an in-depth understanding of the basic connotation of community public safety, a large number of references and actual surveys show that the construction of an urban community public safety indicator system should follow the following principles:

(i) First, the system principle. The indicator system consists of 3 secondary indicators and 21 tertiary indicators. These 24 indicators form a system, interact with each other, and their selection has a certain purpose [25].

(ii) Second, the principle of typical indicators. When selecting indicators, this article strives to use a small number of core indicators to reflect the key content, so as to reduce the energy dispersion of the evaluation subject [26].

(iii) Third, the operational principle. When selecting the public safety evaluation indicators of urban communities, this paper pays attention to the availability of data and descriptive information of the indicators, which has great application value.

The community public safety evaluation index system established in this article has the following three characteristics:

(1) Comprehensiveness of evaluation indicators: As mentioned above, since the elements of urban communities include subjective and objective elements, if we want to evaluate community public safety, we must start with the subjective and objective elements of the community. The objective elements in 1 refer to the facilities, management system, community culture, and so on of community public safety; the subjective elements refer to people's psychological feelings and values. This article combines the two organically to fully reflect the status quo of community public safety.

(2) Comprehensiveness of evaluation subject: On the basis of the previous evaluation subjects of community work, that is, experts, scholars, and intermediary organizations, community residents committees and property companies, neighborhoods and the Ministry of Civil Affairs, and community residents organizations, individual community residents are included in the scope of the evaluation subjects. The direct participation of residents in the evaluation of community public safety not only makes the subject of community public safety evaluation more comprehensive, but also makes the evaluation of community public safety more realistic.
(3) Composition of community safety evaluation index system

Drawing lessons from the research results of "safe communities," "disaster reduction communities," "community public security," and "community policing" and using the above-mentioned index selection methods, this paper initially established a community public safety index system based on the location information service architecture, as shown in Table 1. This article mainly considers the safety of residents living in the community and the impact of various activities and events in the community on the safety of residents. And based on the location information service system, community residents are regarded as one of the important subjects of community public safety evaluation to evaluate the status quo of community public safety.

\section{Community Public Safety Evaluation System Based on Location Information Service Architecture}

4.1. Community Public Security Situation Analysis. According to the foregoing, this study uses sample surveys and questionnaires to collect qualitative data. According to the content of the research, a questionnaire was drawn up, and with the assistance of the neighborhood committee of the community, the public safety status of the community was investigated. A total of 500 questionnaires were distributed and 480 valid questionnaires were returned. The distribution ratio is 10 copies for community neighborhood committees, 10 copies for community police officers and security guards, 5 copies for community property companies, 10 copies for community residents' organizations, 5 copies for district units, and a total of 440 copies for ordinary residents based on households. The evaluation subjects involve quasicommunity management organizations, community residents' organizations, district units, and ordinary residents, and community residents account for more than $85 \%$ of the evaluation subjects. The quantitative data of this study include data on various accidents and social security incidents in the community, provided by the neighborhood committee of the community. In the five years from 2015 to 2019, a summary of public safety incidents caused by various subjective and objective factors in a community is shown in Table 2 .

\subsection{Weights of Community Public Safety Evaluation} Indicators. Weight is a relative concept, which refers to a certain index. The weight of a certain index refers to the relative importance of the index in the overall evaluation, and the weight setting of the public safety evaluation index of urban communities reflects the importance of the index in the process of achieving the goal of community safety. The weight ratios of different factors selected in this paper are different. As shown in Table 3, they are mainly determined by a comprehensive method combining expert judgment and fuzzy judgment. 
TABLE 1: Community public safety evaluation index system.

\begin{tabular}{|c|c|c|}
\hline Secondary indicators & Level three indicators & Evaluation method \\
\hline Public safety perception & $\begin{array}{c}\text { Community public order } \\
\text { Familiarity of community residents } \\
\text { Goodness of community property management } \\
\text { Community traffic, greening, and other environmental goodness } \\
\text { Community education, commerce, medical, health, and other supporting facilities are good } \\
\text { Population mobility rate } \\
\text { Police (security) working methods } \\
\text { Good police management } \\
\text { Subjectively perceived degree of criminal threat }\end{array}$ & $\begin{array}{l}\text { Questionnaire } \\
\text { Questionnaire } \\
\text { Questionnaire } \\
\text { Questionnaire } \\
\text { Questionnaire } \\
\text { Questionnaire } \\
\text { Questionnaire } \\
\text { Questionnaire } \\
\text { Questionnaire }\end{array}$ \\
\hline Nonhuman factors & $\begin{array}{l}\text { Frequency of earthquakes and volcanoes } \\
\text { Frequency of meteorological disasters } \\
\text { Frequency of mudslides } \\
\text { Frequency of accidental injuries }\end{array}$ & $\begin{array}{l}\text { Data review } \\
\text { Data review } \\
\text { Data review } \\
\text { Data review }\end{array}$ \\
\hline Human factors & $\begin{array}{c}\text { Frequency of public security incidents } \\
\text { Food and drug hygiene and safety } \\
\text { Water area safety } \\
\text { Drinking water safety } \\
\text { Probability of infectious disease incidents } \\
\text { Suicide incidence } \\
\text { Incidence of domestic violence } \\
\text { Domestic water, electricity, and gas safety }\end{array}$ & $\begin{array}{l}\text { Data review } \\
\text { Data review } \\
\text { Data review } \\
\text { Data review } \\
\text { Data review } \\
\text { Data review } \\
\text { Data review } \\
\text { Data review }\end{array}$ \\
\hline
\end{tabular}

TABLE 2: Statistics of public safety incidents that occurred in a community from 2015 to 2019.

\begin{tabular}{lcc}
\hline Index & Occurrence frequency & Evaluation \\
\hline Frequency of public security incidents & 14 cases, including 8 burglaries $(4$ criminal cases $)$ & D \\
Food and drug hygiene and safety & 0 & 0 \\
Water area safety & 0 & A \\
Drinking water safety & 0 & A \\
Probability of infectious disease incidents & 0 & A \\
Suicide incidence & A cases filed at the police station \\
Incidence of domestic violence & 2 cases \\
Domestic water, electricity, and gas safety & 0 & A \\
Frequency of earthquakes and volcanoes & 0 & A \\
Frequency of meteorological disasters & 0 & D \\
Frequency of mudslides & 0 & A \\
Frequency of accidental injuries & A \\
\hline
\end{tabular}

It can be seen from Figure 2 that the evaluation indicators we have selected are different in their importance to the public safety of urban communities. In order for the evaluation indicators to truly and accurately reflect the status quo and management level of community public safety, different indicators give different weights.

It can be seen from Table 4 that the community public safety objective indicator comment set we made was evaluated based on the range of casualties that occurred within five years. It is undeniable that there are indeed some uncertain factors, such as unregistered casualties.

It can be seen from Figure 3 that the distribution of community public safety evaluation grades is ABCD four grades, based on the number of deaths and the number of casualties in five years.

4.3. Results of Community Public Safety Evaluation System Based on Location Information Service Architecture. This study defines the " $A$ " level full score as 100 points, and the formula $b_{j}=(n+1-j) \times 100 / n(j=1,2, \ldots, n)$. Using the arithmetic scoring method, we get 75 points for " $\mathrm{B}$ ” level, 50 points for " $C$ " level, and 25 points for " $D$ " level. Using the principles mentioned above, through program calculation, the scores of the three-level indicators of the community public safety evaluation are shown in Tables 5-7. After calculating the three-level indicators, the scores of the second-level indicators are obtained, as shown in Table 8.

The subjective perception of community public safety includes three levels of indicators. As shown in Table 5 and Figure 4, there are community public order indicators, community greening indicators, and sanitary environment indicators. Among them, the sanitary environment index scored the highest, 88.57 points, because the community is located on the mountain, has a very good advantage, and do a good job in air purification and hygiene maintenance. The residents of the community have relatively good social relations. The residents living in it are familiar with their 
TABLE 3: Community public safety index weight table.

\begin{tabular}{|c|c|c|c|c|}
\hline First level indicator & $\begin{array}{l}\text { Secondary } \\
\text { indicators }\end{array}$ & Weights & Level three indicators & Weights \\
\hline \multirow{21}{*}{$\begin{array}{l}\text { Community public } \\
\text { safety }\end{array}$} & \multirow{9}{*}{$\begin{array}{l}\text { Public safety } \\
\text { perception }\end{array}$} & \multirow{9}{*}{0.28415} & Community public order & 0.1526 \\
\hline & & & Familiarity of community residents & 0.084948 \\
\hline & & & Goodness of community property management & 0.11482 \\
\hline & & & Community traffic, greening and other environmental goodness & 0.12009 \\
\hline & & & $\begin{array}{c}\text { Community education, commerce, medical, health, and other } \\
\text { supporting facilities are good }\end{array}$ & 0.1012 \\
\hline & & & Population mobility rate & 0.052438 \\
\hline & & & Police (security) working methods & 0.12009 \\
\hline & & & Good police management & 0.13635 \\
\hline & & & Subjectively perceived degree of criminal threat & 0.11746 \\
\hline & \multirow{4}{*}{ Nonhuman factors } & \multirow{4}{*}{0.27388} & Frequency of earthquakes and volcanoes & 0.25226 \\
\hline & & & Frequency of meteorological disasters & 0.28675 \\
\hline & & & Frequency of mudslides & 0.20492 \\
\hline & & & Frequency of accidental injuries & 0.25607 \\
\hline & \multirow{8}{*}{ Human factors } & \multirow{8}{*}{0.44197} & Frequency of public security incidents & 0.12696 \\
\hline & & & Food and drug hygiene and safety & 0.16722 \\
\hline & & & Water area safety & 0.10593 \\
\hline & & & Drinking water safety & 0.16722 \\
\hline & & & Probability of infectious disease incidents & 0.14798 \\
\hline & & & Suicide incidence & 0.048227 \\
\hline & & & Incidence of domestic violence & 0.088488 \\
\hline & & & Domestic water, electricity, and gas safety & 0.14798 \\
\hline
\end{tabular}

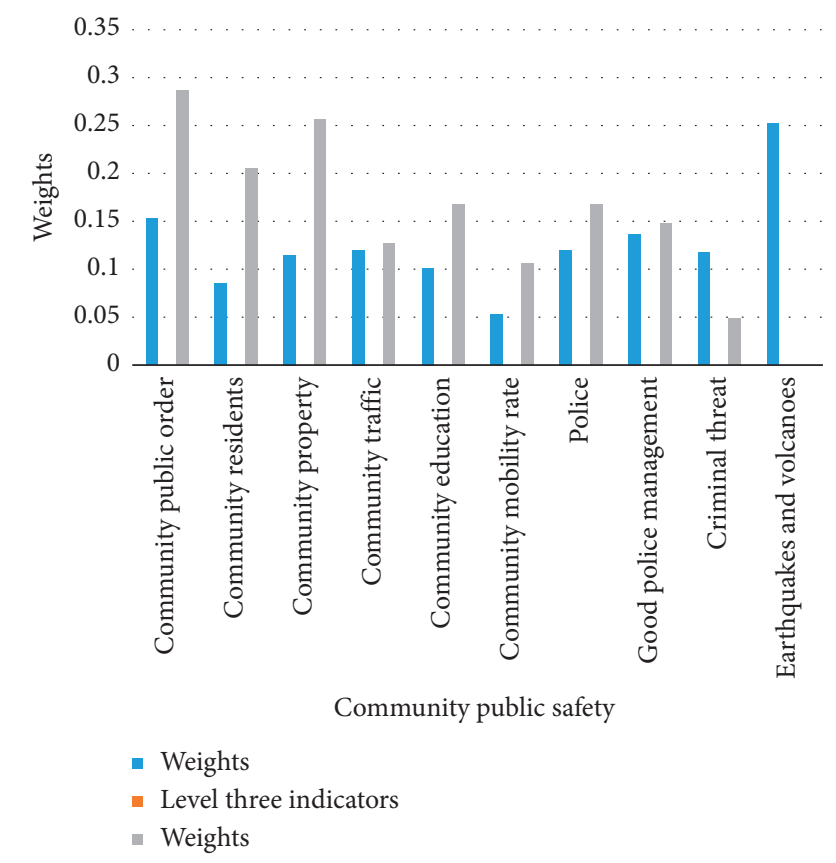

Figure 2: Statistics of public safety incidents that occurred in the community from 2015 to 2019.

TABLE 4: Comment collection of objective indicators of community public safety.

\begin{tabular}{lc}
\hline $\begin{array}{l}\text { Evaluation item level (number of occurrences within } \\
\text { five years) }\end{array}$ & Comments \\
\hline $1-3$ (no casualties) & $\mathrm{A}$ \\
$4-7$ (casualties $<3)$ & $\mathrm{B}$ \\
$8-12$ (casualties $<5)$ & $\mathrm{C}$ \\
13 times or more $($ casualties $>6)$ & $\mathrm{D}$ \\
\hline
\end{tabular}

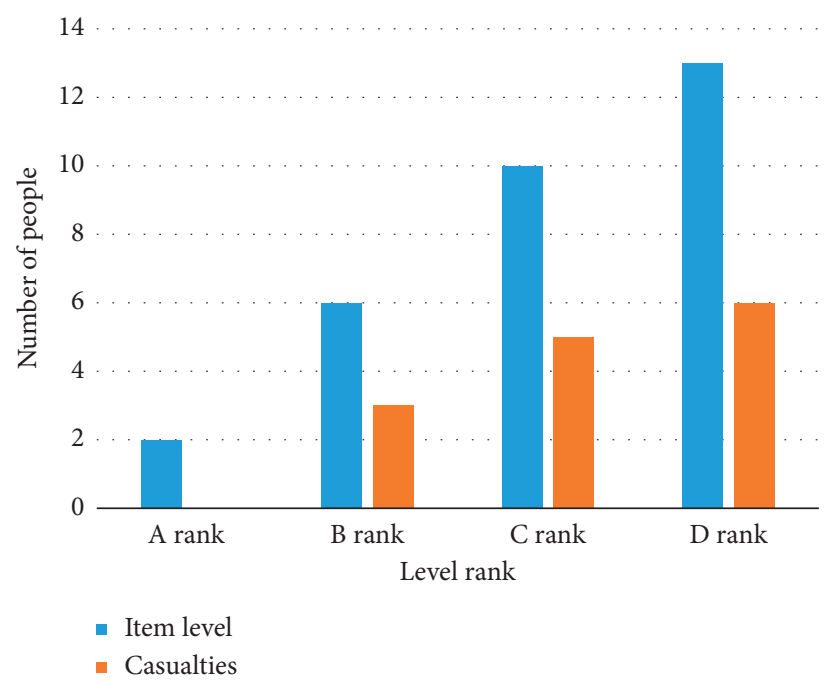

Figure 3: Comment collection of objective indicators of community public safety.

neighbors and can take care of each other. The population mobility rate in the community is relatively small, and most of them are permanent households. The various supporting facilities in the community are not particularly satisfactory. In addition, there may be some community residents who do not agree with the working methods of the community police or security guards are not satisfied with their work efficiency, etc., but can still maintain a good relationship with the police or security guards and can provide cooperation. The more prominent problem is that the community's property management status is not satisfactory, and the score is the lowest, only 56.38 points. Therefore, 
TABLE 5: Community public safety survey score sheet.

\begin{tabular}{lr}
\hline Level three indicators & Scores \\
\hline Community public order & 77.03 \\
Familiarity of community residents & 73.92 \\
Goodness of community property management & 56.38 \\
Community traffic, greening and other environmental goodness & 88.57 \\
Community education, commerce, medical, health, and other supporting facilities are good & 64.30 \\
Population mobility rate & 75.67 \\
Police (security) working methods & 68.89 \\
Good police management & 75.52 \\
Subjectively perceived degree of criminal threat & 86.33 \\
\hline
\end{tabular}

TABLE 6: Community public safety survey score sheet-nonhuman factors.

\begin{tabular}{lc}
\hline Level three indicators & Scores \\
\hline Frequency of earthquakes and volcanoes & 100 \\
Frequency of meteorological disasters & 100 \\
Frequency of mudslides & 100 \\
Frequency of accidental injuries & 100 \\
\hline
\end{tabular}

TABle 7: Community public safety survey score sheet-human factors.

\begin{tabular}{lc}
\hline Level three indicators & Scores \\
\hline Frequency of public security incidents & 25 \\
Food and drug hygiene and safety & 100 \\
Water area safety & 100 \\
Drinking water safety & 100 \\
Probability of infectious disease incidents & 100 \\
Suicide incidence & 100 \\
Incidence of domestic violence & 100 \\
Domestic water, electricity, and gas safety & 25 \\
\hline
\end{tabular}

community residents' associations, property companies, and related departments should start from the aspects of hardware and environment and strive to meet the needs of community residents in this regard, so that they can feel more secure.

It can be seen from Table 6 that events caused by nonhuman factors have the least impact on community public safety, and the scores are all within the range of "A." However, the community is located in a mountainous area. If the mountain forest is not well protected, it is very easy to cause soil erosion, which will lead to the occurrence of mudslides. Although the evaluation score is still " $\mathrm{A}$," it is necessary to pay attention to preventive measures. Through interviews, it is learned that the community has no disaster emergency plan and no training or education of community residents on relevant content. Therefore, early warning and education mechanisms for preventing meteorological and other disasters should be established and improved as soon as possible. In addition, the establishment of LBS for emergency situations can issue rescue at the first time when natural disasters occur, remove all obstacles through location information services, and use RFID technology to send signals of different frequencies to quickly locate community residents, bringing huge benefits to the public sense of security.

There are 8 man-made factors that affect the public safety of the community. It can be seen from Table 7 that the frequency of public security cases is relatively high. At the same time, there are great hidden dangers in the safety of household gas and electricity. It can be considered to strengthen the LBS location information service, mark the location based on areas where public security incidents frequently occur, upload the information to the cloud platform to strengthen security patrols in the area, and reduce the occurrence of security accidents. At the same time, according to RFID technology, the safety of water, electricity, and gas use in residents' homes is detected, hidden dangers are investigated, and the frequency of accidents is reduced.

It can be seen from Table 8 that the public safety perception of the community is 63.7152 points, nonhuman factors are 100 points, and human factors are 65.8560 points. The comparison of the three is shown in Figure 5. On the basis of the existing secondary index scores, it can be calculated that the community's public safety evaluation score is 62.6232 points, that is, the community's public safety status is "average."

The previous explanation of the uncertainty of human factors supporting data can be used to explain the uncertainty of nonhuman factors data. In urban communities, it is unrealistic for the number of accidental injuries to be " 0 ." Accidental injuries may have occurred. However, because the incident is within the scope of a minor incident, the residents have not filed with the police station in the jurisdiction or notified the neighborhood committee, so it is acceptable. Its evaluation score is "A." Among the three secondary indicators, the evaluation subject believes that human factors are the biggest cause of community public safety incidents. The public safety perception score is 63.7152, but the "subjectively felt criminal threat" score is 86.33. This outstanding comparison shows that community residents are more satisfied with the safety of the community, but there are still greater hidden dangers.

In general, this community belongs to the "general" ranks of the current public safety. In the future construction, we should focus on strengthening the construction of location information services, strengthening the connection between the police platform and the mobile information platform, strengthening the upload and output of cloud data, 


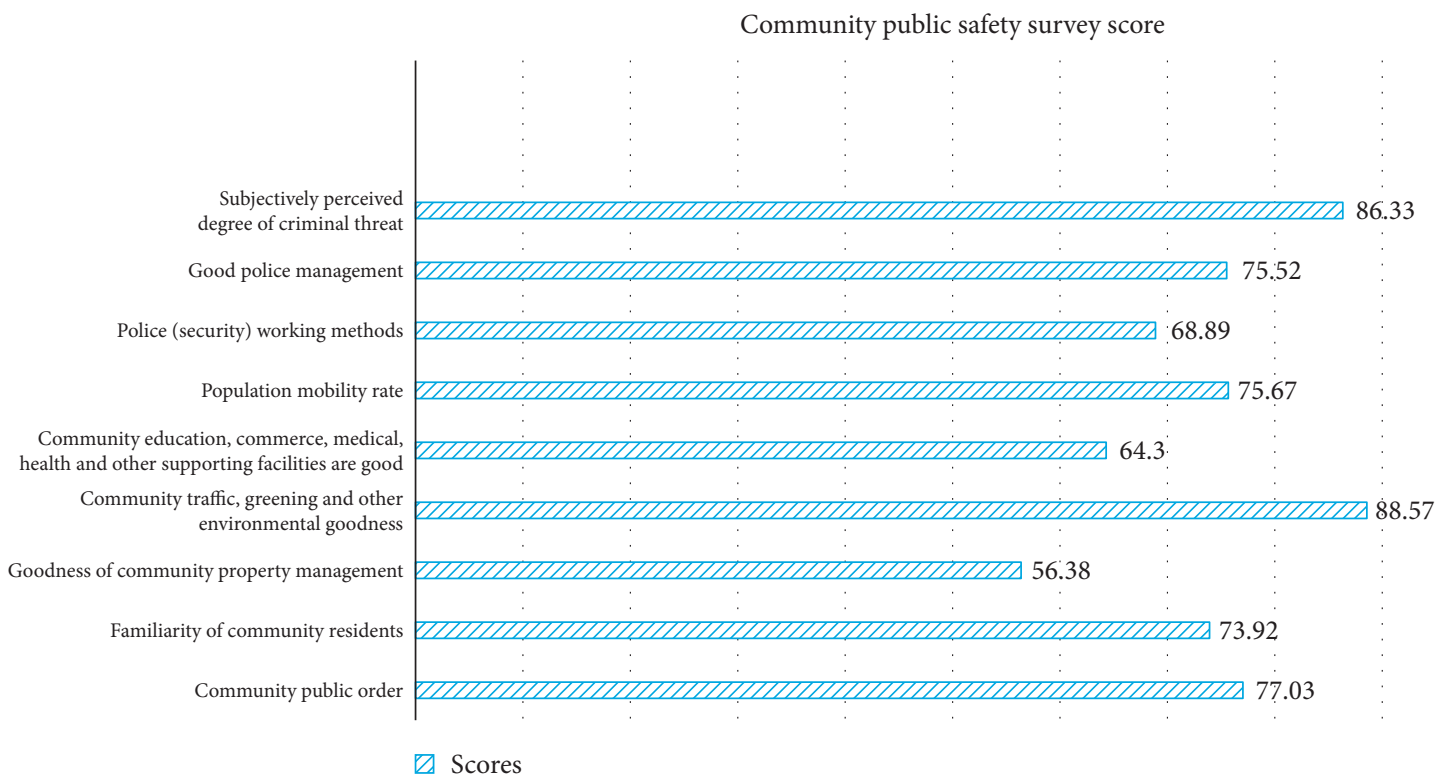

Figure 4: Community public safety survey score.

TABLE 8: Community public safety survey score-secondary indicators.

\begin{tabular}{lc}
\hline Secondary indicators & Scores \\
\hline Public safety perception & 63.7152 \\
Objective factors & 100 \\
Subjective factors & 65.8560 \\
\hline
\end{tabular}

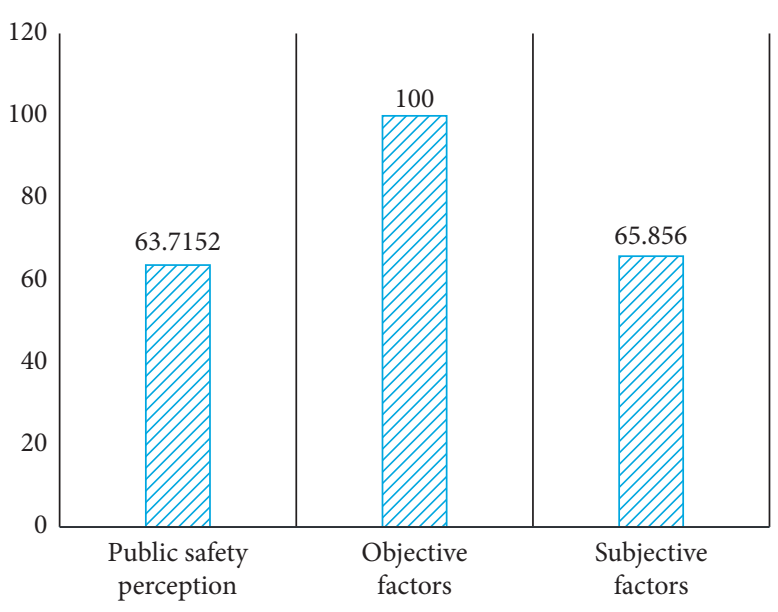

$Z$ Scores

Figure 5: Community public safety survey score-secondary indicators.

and improving the police. The work efficiency of administrative staff ensures the safety of community residents and reduces the loss of community residents. At the same time, the role of the property company should also be played to supervise its truly responsible services for residents, so as to gain more support from community residents and improve the sense of security and happiness of community residents.

\section{Conclusions}

This article mainly studies the community public safety evaluation based on the location information service structure. Through the combination of theory and practice, qualitative and quantitative research, LBS model, and community public safety evaluation system are established. The importance and feasibility of adding location information services to security construction.

This article mainly adopts the social survey method, fuzzy comprehensive evaluation method, and community safety evaluation method that joins LBS location information service and incorporates residents into the evaluation subject, which fully reflects the subjectivity of community residents and encourages residents to truly participate in the community. Safety construction is coming.

The shortcomings of this article are (1) the location information service architecture is still in the development stage. Although the location information of residents can be obtained, there are also security and privacy issues. The issue of how to protect users' social privacy remains to be resolved. (2) Due to the limitations of funds, time, and energy, the number of questionnaires issued this time is limited and the coverage rate is not high enough. (3) Because the sampling survey method and questionnaire survey method are adopted and no in-depth interviews are conducted, the evaluation subjects' understanding of the questionnaires is inconsistent, resulting in the result contains uncertain factors.

\section{Data Availability}

No data were used to support this study

\section{Conflicts of Interest}

The author declares no conflicts of interest. 


\section{Acknowledgments}

This project was entrusted by enterprises and institutions of Peking University ("Research on the management mode innovation of community public security service in China" research findings, Project no: 2019002514 and Project leader: Hengxue Huang).

\section{References}

[1] W. Yu, "Spatial co-location pattern mining for location-based services in road networks," Expert Systems with Applications, vol. 46, pp. 324-335, 2016.

[2] S. Tulumello, "The multiscalar nature of urban security and public safety: crime prevention from local policy to policing in Lisbon (Portugal) and Memphis (the United States)," Urban Affairs Review, vol. 54, no. 6, pp. 1134-1169, 2017.

[3] C. Lapsley, "Public safety is a shared responsibility," Asia Pacific Fire Magazine, vol. 70, pp. 38-40, 2019.

[4] W. Zhou, J. Hou, W. Fan et al., "A location-based marine fishery information service based on BeiDou navigation satellite system," Journal of Intelligent and Fuzzy Systems, vol. 37, no. 4, pp. 1-8, 2019.

[5] T. Kim, "A study on the security technology of the location based tourism information service," Journal of the Korea Society of Digital Industry and Information Management, vol. 12, no. 2, pp. 25-29, 2016.

[6] L. Niu, "Adaptive aggregation service for indoor location information using cloud," Computer Speech \& Language, vol. 5, no. 4, pp. 341-362, 2016.

[7] S. S. Kashi, "A load balanced location service for location information management of multi-sink wireless sensor networks," Computing, vol. 100, no. 2, pp. 1-25, 2017.

[8] L. Chen, F. Xie, Z. Zheng, and Y. Wu, "Predicting quality of service via leveraging location information," Complexity, vol. 2019, Article ID 4932030, 16 pages, 2019.

[9] R. Rajadurai, K. S. Gopalan, M. Patil, and S. Chitturi, "Enhanced interworking of LTE and wi-fi direct for public safety," IEEE Communications Magazine, vol. 54, no. 4, pp. 40-46, 2016.

[10] R. C. Eric, "Microgrids in Maryland: bolstering public safety, community resiliency," District Energy, vol. 104, no. 3, pp. 12-16, 2018.

[11] A. M. Zambrano, X. Calderón, S. Jaramillo, O. M. Zambrano, M. Esteve, and C. Palau, "3-community early warning systems," Wireless Public Safety Networks 3, Elsevier, Amsterdam, Netherlands, pp. 39-66, 2017.

[12] A. A. Alkheir and H. T. Mouftah, "10-Cognitive radio for public safety communications," Wireless Public Safety Networks 2: Applications and Uses, Elsevier, Amsterdam, Netherlands, pp. 295-316, 2016.

[13] J. Cohen, M. Reddish, and N. Zimbelman, "APCO recognizes leaders in public safety communications," Public Safety Communications, vol. 84, no. 3, pp. 11-13, 2018.

[14] J. Cohen, "Recognizing leaders in public safety communications," Public Safety Communications, vol. 82, no. 3, pp. 11-12, 2016.

[15] J. L. Beatty, "Medical privacy vs. Public safety?" Aerosafety World, vol. 11, no. 3, p. 1, 2016.

[16] G. Bhawnani, "Rule of the "lawless law" detentions under the public safety act in Kashmir," Economic and Political Weekly, vol. 53, no. 20, pp. 36-41, 2018.

[17] S. W. Formica, R. Apsler, L. Wilkins, S. Ruiz, B. Reilly, and A. Y. Walley, "Post opioid overdose outreach by public health and public safety agencies: exploration of emerging programs in Massachusetts," International Journal of Drug Policy, vol. 54, pp. 43-50, 2018.

[18] L. Sakala and N. L. Vigne, "Community-driven models for safety and justice," Du Bois Review Social Ence Research on Race, vol. 16, no. 1, pp. 1-14, 2019.

[19] M. Dragoicea, M. Leonard, S. N. Ciolofan, and G. Militaru, "Managing data, information, and technology in cyber physical systems: public safety as a service and its systems," IEEE Access, vol. 7, no. 99, pp. 92672-92692, 2019.

[20] B. N. Williams, R. S. Brower, and W. E. Klay, "Communitycentred police professionalism," The Police Journal: Theory, Practice and Principles, vol. 89, no. 2, pp. 151-173, 2016.

[21] T. R. Byrdsong, A. Devan, and H. Yamatani, "A ground-up model for gun violence reduction: a community-based public health approach," Journal of Evidence-Informed Social Work, vol. 13, no. 1, pp. 76-86, 2016.

[22] T. P. Abt, "Towards a framework for preventing community violence among youth," Psychology, Health \& Medicine, vol. 22, no. sup1, pp. 266-285, 2017.

[23] R. M. Peters, T. J. Hipper, and E. D. Chernak, "Primary care medical practices: are community health care providers ready for disasters?" Disaster Medicine and Public Health Preparedness, vol. 13, no. 2, pp. 128-132, 2019.

[24] L. Wahowiak, "New rankings showcase community health," American Journal of Public Health, vol. 108, p. 967, 2018.

[25] H. Sutton, "Find ways to make yourself essential to your offcampus community," Campus Security Report, vol. 13, no. 7, pp. 1-5, 2016.

[26] Z. Hamilton, C. M. Campbell, J. vanWormer et al., "Impact of swift and certain sanctions: evaluation of Washington state's policy for offenders on community supervision," Criminology \& Public Policy, vol. 15, no. 4, pp. 1-64, 2016. 